\title{
DOES INTRAOPERATIVE ULTRASOUND EXAMINATION IMPROVE THE DETECTION OF HEPATIC METASTASES OF PANCREATIC CARCINOMA?
}

\author{
Ivaylo Vazharov \\ Department of Gastroenterology, Naval Hospital of Varna, \\ Military Medical Academy of Sofia
}

\begin{abstract}
PURPOSE: The aim of the study was to estimate the value of intraoperative ultrasound (IOUS) in detecting the hepatic metastases of pancreatic carcinoma.

MATERIAL AND METHODS: A total of 16 patients, 6 women and 9 men, were considered suitable for hepatic resection of pancreatic carcinoma with transcutaneous ultrasound examination (US) and contrast enhanced computer tomography. Intraoperatively, they are examined by inspection, bimanual palpation and US. Both number and localization of the lesions were compared. IOUS influence on the operative plan was evaluated.

RESULTS: IOUS detected 60 liver metastases which were histologically confirmed. Preoperative US examination found out 28 lesions or $46,66 \%$ of all lesions and the preoperative computer tomography (CT) did 29 ones or $48,33 \%$. The information gained from IOUS changed the operative plan in 8 out of 16 patients. A biliary stent was placed under IOUS control in one patient with severe hyperbilirubinemia of $466 \mu \mathrm{mol} / \mathrm{L}$.
\end{abstract}

CONCLUSION: IOUS detects by more than two times hepatic metastases in comparison to the preoperative US and CT. It enables the change of the medical strategy in half of the patients and in the patients with mechanical icterus. Besides it allows stent placement to alleviate patient's status. This leads us to the conclusion that IOUS should be applied as a routine practice in hepatic resections of pancreatic carcinoma metastases.

Key words: preoperative ultrasound, computer tomography, intraoperative ultrasound, pancreatic carcinoma, biliary stent

\section{INTRODUCTION}

Intraoperative ultrasound (IOUS) is used in the operative treatment of primary and secondary hepatic tumours since the 70 's of the $20^{\text {th }}$ century onwards (8). IOUS can detect additional lesions, especially

Address for correspondence:

Ivaylo Vazharov, $M D, P h D$

Department of Gastroenterology,

Naval Hospital of Varna,

Military Medical Academy of Sofia

3 Hristo Smirnenski Str.

9010 Varna, Bulgaria

E-mail:vajarov@dir.bg

Received: November 28, 2012

Accepted: January 15, 2013 in metastatic neoplasms (2), it alters the surgical strategy in some patients (3) and helps preserving the hepatic parenchyma. When the operation is radical, this method defines the interrelations between the tumour and the vascular network (9).

There are studies about the limited clinical value of IOUS $(4,5)$ in detecting hepatic metastases of pancreatic cancer.

For these reasons we decided to assess the value of IOUS in detecting such liver metastases.

\section{MATERIAL AND METHODS}

The study covered 16 patients, 9 males and 6 females who had undergone operative intervention 
for pancreatic carcinoma with hepatic metastases during the period 2007-2012. Patients' average age was 65 years (range, 56-77 years). Fifteen patients presented with synchronous metastases and one patient with metachronous ones.

The liver was examined by US and CT preoperatively and during the surgical intervention by inspection, palpation and IOUS.

The examination was approved by the Ethic Committee of the Naval Hospital of Varna, Military Medical Academy. All the patients signed an informed consent before the examination and operation. All the procedures were in conformity with the requirements of the good clinical practice and ethical standards of the World Medical Association (Declaration from Helsinki for the rights of the examined patients).

\section{RESULTS}

The maximum number of malignant hepatic lesions was 70 (Fig. 1). All of them were histologically confirmed. Twenty-eight lesions or $46,66 \%$ of all the lesions were found out by using preoperative US examination and 29 ones $(48,33 \%)$ were established by means of preoperative CT (Fig. 1).

A total of 33 lesions sized $<20 \mathrm{~mm}$ were detected by IOUS, 5 ones by CT and 3 ones by US. A total of 28

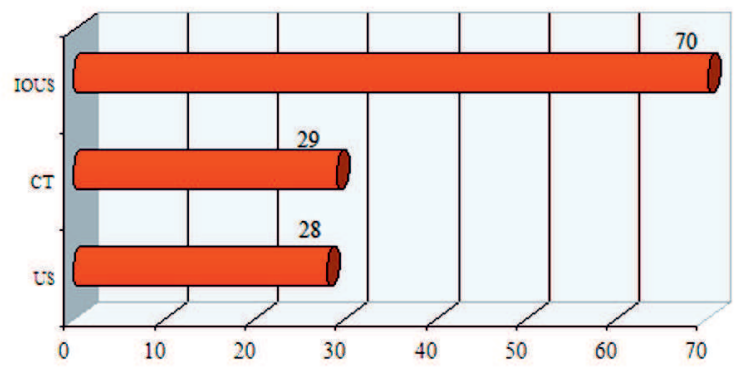

Fig. 1. Number of metastases revealed by IOUS, US and CT

lesions of a size between 20 and $30 \mathrm{~mm}$ were detected by IOUS, 25 by CT and 13 by US. Concerning the larger lesions, these three methods revealed comparable amounts of liver metastases (Fig. 2).

IOUS determined exactly the location of the metastases/The most commonly affected liver segments were IV, II and III according to Couinaud's

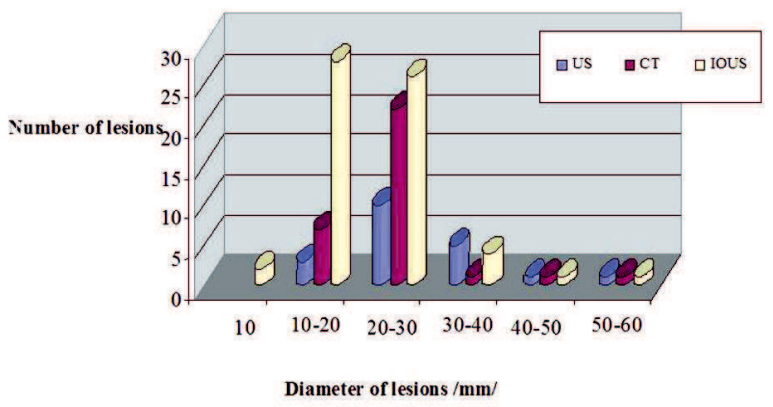

Fig. 2. Number of lesions of different size detected by IOUS, US and CT

Table 1. Number of metastases inn different liver segments detected by IOUS, US and CT

\begin{tabular}{|l|c|c|c|c|c|c|c|c|c|}
\hline \multirow{2}{*}{$\begin{array}{l}\text { Diagnostic } \\
\text { method }\end{array}$} & \multicolumn{8}{|c|}{ Pancreatic carcinoma/Liver segments } & \multirow{2}{*}{$\begin{array}{c}\text { Total MLL } \\
\text { number }\end{array}$} \\
\cline { 2 - 7 } & I & II & III & IV & V & VI & VII & VIII & \\
\hline US & - & 4 & 3 & 6 & 4 & 6 & 3 & 2 & 28 \\
CT & - & 3 & 2 & 7 & 5 & 6 & 4 & 3 & 29 \\
IOUS & - & 13 & 12 & 14 & 8 & 9 & 7 & 7 & 70 \\
\hline \hline
\end{tabular}

Table 2. Distribution of echogenicity of lesions revealed by US and IOUS

\begin{tabular}{|c|c|c|c|c|c|c|}
\hline \multirow{2}{*}{$\begin{array}{l}\text { Diagnostic } \\
\text { method }\end{array}$} & \multicolumn{5}{|c|}{ Lesions detected by different ultrasound type } & \multirow{2}{*}{$\begin{array}{c}\text { Total MLL } \\
\text { number }\end{array}$} \\
\hline & $\begin{array}{l}\text { Hyper- } \\
\text { echogenic }\end{array}$ & $\begin{array}{l}\text { Hypo- } \\
\text { echogenic }\end{array}$ & $\begin{array}{c}\text { Mixed } \\
\text { echogenic }\end{array}$ & Isoechogenic & 'Buffalo eye' & \\
\hline US & 2 & 14 & 6 & 3 & 3 & 28 \\
\hline IOUS & - & 13 & 38 & 14 & 5 & 70 \\
\hline
\end{tabular}

Scripta Scientifica Medica, 2013, vol. 45 (1), pp. 62-65

Copyright (C) Medical University - Varna 
classification (Table 1). The structural inhomogeneity in the region of the hepatic hilus could, probably, better explain the results of IOUS. Table 2 illustrated US appearance of the metastatic hepatic lesions according to the diagnostic method used.

A hypoechogenic metastasis measuring $6 / 8 \mathrm{~mm}$ that was not detected by intraoperative palpation was shown on Fig. 3. On Fig. 4 one could observe two isoechogenic metastases without halo and measuring $9 \mathrm{~mm}$ and $10 \mathrm{~mm}$, respectively, in a steatoticliver, hard to distinguish from the surrounding parenchyma. After hepatectomy, however, they were confirmed as metastases.

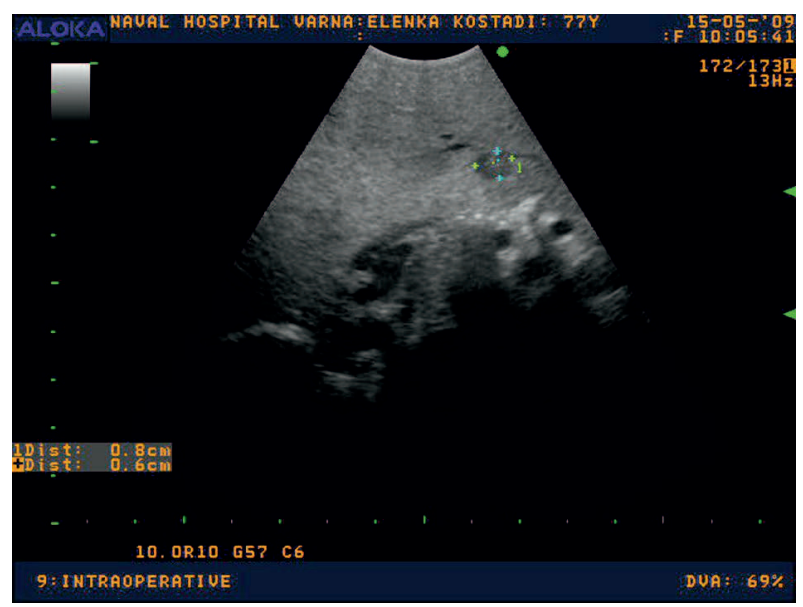

Fig. 3. Hypoechogenic metastasis of pancreatic carcinoma

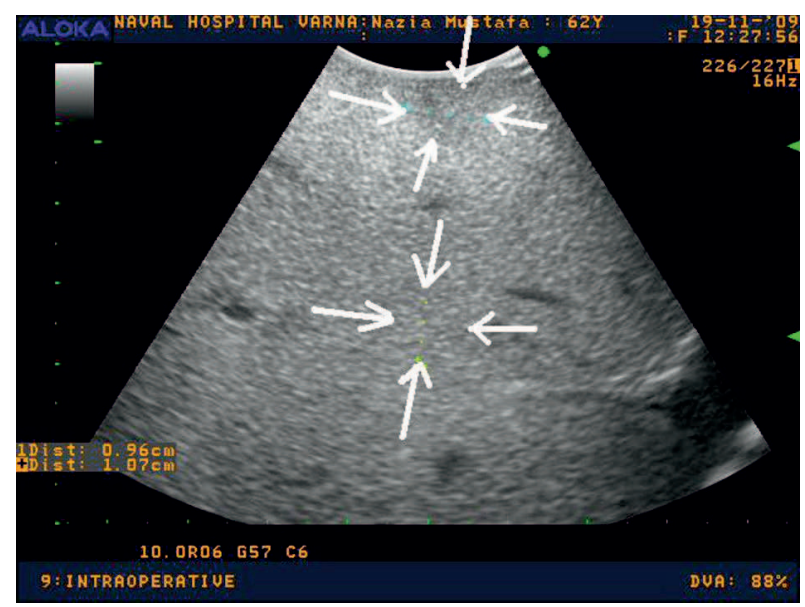

Fig. 4. Two isoechogenic metastases in the steatotic liver of pancreatic carcinoma

The information of IOUS changed the operative plan in $8 /$ out of 16 patients (50\%). A biliary stent under IOUS control was placed in one patient with a severe hyperbilirubinemia of $466 \mu \mathrm{mol} / \mathrm{L}$.

\section{DISCUSSION}

Approximately $90 \%$ of the patients die during the first year after diagnosing the pancreatic carcinoma and, therefore, it remains one of the most important problems in gastroenterology (6). The average age of our patients' group is 65 years which is lower in comparison to the data of the surveillance, epidemiology and end results (SEER) trial that in 2004-2008, the average age of diagnosing this carcinoma is 72 years and the average age of death is 73 years (10). Besides liver metastases are predominantly synchronous (in 15 out of 16 patients or in $93,75 \%$ of the cases).

The number of lesions detected by IOUS considerably exceeds the number of those established by the other two diagnostic methods. IOUS detects 70 metastases which are by two times more than these detected by CT and US. The average number of lesions found out in one patient by IOUS is over four, while the preoperative diagnostic methods detect less than two lesions only.

The analysis of the groups shows a great difference in detecting the malignant lesions by the preoperative imaging methods such as US and CT, on one hand, and IOUS, on the other hand, measuring is size between 10 and $20 \mathrm{~mm}$.

A total of 33 lesions sized $<20 \mathrm{~mm}$ were detected by IOUS, 5 ones by CT and 3 ones by US. A total of 28 lesions of a size between 20 and $30 \mathrm{~mm}$ were detected by IOUS, 25 by CT and 13 by US. A total of 33 out of 70 metastases $(47,14 \%)$ of pancreatic carcinoma in our study are smaller than $20 \mathrm{~mm}$ in size. The average size of all the metastases is $21,88 \mathrm{~mm}$ in IOUS, $29,84 \mathrm{~mm}$ in CT and $33,08 \mathrm{~mm}$ in US. This is true for $95 \%$ of the cases where the three methods of imaging diagnostics are consecutively used. The minimum size of the metastases found by IOUS, CT and US is $10 \mathrm{~mm}, 19 \mathrm{~mm}$ and $18 \mathrm{~mm}$, respectively. Most metastases are of mixed echogenicity $(54,2 \%)$, a small part of them are isoechogenic (20\%) and hypoechogenic $(18,6 \%)$. It is an interesting fact that preoperative US examination establishes only 6 metastases $(21,4 \%)$ of mixed echogenicity. This 
discrepancy can be explained with the greater resolution of IOUS enabling the detection of more details of the examined structure.

The metastases show an almost regular distribution in both lobes of the liver. In IOUS, 39 out of 70 of the lesions $(55,7 \%)$ are in the left hepatic lobe and 31 out of $70(44,3 \%)$ - in the right one. Most metastases are observed in IV segment $(12 / 60 ; 20 \%)$ followed by those in II segment $(11 / 60 ; 18,33 \%)$, and in III segment $(10 / 60 ; 16,66 \%)$. The segments VII and VIII present with least metastases - 6/60 (10\%) eachh. No metastases are establisehd in the first segment. There is thrombosis of $\mathrm{v}$. hepatica in one patient in this group.

According to the pathologists, there is no other organ giving metastases in the liver of such small size (7). In our study the metastases of pancreatic carcinoma have an average size of $21,88 \mathrm{~mm}$ and $33 / 70$ of the malignant hepatic lesions are smaller than $20 \mathrm{~mm}(47,14 \%)$.

According to the literature data, $35-40 \%$ of the cases of pancreatic carcinoma considered as resectable after CT, MRI, endoscopic retrograde cholangiopancreatography and angiography turned out to be inoperable due to hepatic metastases not proved by the preoperative examinations (1). In our study multiple bilobar lesions (43,75\%) are detected in 7 patients who are not suitable for resection. Four of them were revealed by IOUS and the other ones by intraoperative inspection and palpation. Three patients could not be resected because of advanced primary process. This suggests that the pancreatic carcinoma is detected either at an advanced stage of the primary malignancy, or at a stage of multiple hepatic metastases as a marker of poor prognosis.

\section{CONCLUSION}

IOUS detects by more than two times hepatic metastases in comparison to the preoperative US and CT. It helps changing the medical strategy in half of the patients and in the patients with mechanical jaundice and allows stent placement to alleviate patient's status. We can draw the conclusion that IOUS should be applied as a routine practice in hepatic resections of pancreatic carcinoma metastases.

\section{REFERENCES}

1. Cerwenka, H., H. Bacher, G. Werkgartner, A. ElShabrawi, P. Kornprat, H. J. Mischinger, J. Raith. Accuracy of preoperative routine MRI for hepatic lesion detection.- Clin. Imaging, 30, 2006, No 3, 186-189.

2. Conlon, R., M. Jacobs, D. Dasgupta, J. P. Lodge. The value of intraoperative ultrasound during hepatic resection compared with improved preoperative magnetic resonance imaging.- Eur. J. Ultrasound, 16, 2003, No 3, 211-216.

3. D'Hondt, M., F. Vandenbroucke-Menu, S. PrévilleRatelle, S. Turcotte, M. Chagnon, M. Plasse, et al. Is intra-operative ultrasound still useful for the detection of a hepatic tumour in the era of modern pre-operative imaging?- $H P B(O x f o r d), 13,2011$, No 9, 665-669.

4. Finlayson, C., J. Hoffman, R. Yeung, H. Kessler, M. Guttmann, A. Shaer, M. Clair. Intraoperative ultrasound does not improve detection of liver metastases in resectable pancreatic cancer.- Am. J. Surg., 175, 1998, No 2, 99-101.

5. Flati, G., D. Flati, B. Porowska, E. Talarico, D. Tuscano, C. Talarico, M. la Pinta, M. Carboni. Is intraoperative ultrasonography useful in pancreatic cancer surgery?- G. Chir., 15, 1994, No 6-7, 313-316.

6. Fry, L. C., K. Mönkemüller, P. Malfertheiner. Molecular markers of pancreatic cancer: development and clinical relevance.- Langenbecks Arch. Surg., 393, 2008, No 6, 883-890.

7. Graig, J. Liver.- In: Anderson's Pathology. J. M. Kissane, ed. St. Louis etc., Mosby Co., 1990, 1199-1320.

8. Makuuchi, M., K. Kamiya, M. Sugiura, et al. Ultrasonic examination by electronic scanning during operation.- In: Proceedings of the 32nd Meeting of the Japan Society of Ultrasonics in Medicine. 1977, 129-130.

9. Makuuchi, M., G. Torzilli, J. Machi. History of intraoperative ultrasound.- Ultrasound Med. Biol., 24, 1998, No 9, 1229-1242.

10. Raimondi, S., P. Maisonneuve, A. B. Lowenfels Epidemiology of pancreatic cancer: an overview.Nat. Rev. Gastroenterol. Hepatol., 6, 2009, No 12, 699-708. 